\title{
Effect of insect growth regulator, chromafenozide on the food consumption and metabolic efficiencies of the desert locust
}

\author{
Basiouny A. and Ghoneim K.* \\ Department of Zoology and Entomology, Faculty of Science, Al-Azhar University, Cairo, Egypt
}

\begin{abstract}
The objective of the current investigation was to assess the food deterrence property of chromafenozide and its impact on different food metabolic parameters of the $5^{\text {th }}$ instar nymphs of the desert locust Schistocerca gregaria. For this purpose, three doses (10, 100 and $150 \mu \mathrm{g} / \mathrm{nymph})$ were topically applied (once) onto the newly molted last $\left(5^{\text {th }}\right)$ instar nymphs. chromafenozide exhibited contradictory effects on the feeding since it acted as a weak antifeedant against female nymphs only at the lowest dose but acted as phagostimulant against their congeners at the higher two doses. Furthermore, the compound exerted a general phagostimulant action on the male nymphs, regardless the dose. The food intake by the last nymphal instar females was slightly reduced only at only the lowest dose but remarkably increased at the higher doses. The male nymphs had been promoted to consume more food amount. Treated nymphs of both sexes attained slightly or significantly increasing relative weight gain and discharged more frass pellets. The treated nymphs of both sexes achieved slightly increasing approximate digestibility (AD), with two exceptions for the male nymphs which had a slightly decreased AD at the medium dose and unaffected $\mathrm{AD}$ at the highest dose. Both the efficiency of conversion of ingested food into biomass (ECI) and efficiency of conversion of digested food into biomass (ECD) of the female nymphs slightly increased. ECI of male nymphs was enhanced but ECD was slightly inhibited. Depending on the present results, Chromafenozide cannot be recommended as a promising agent for controlling S. gregaria.
\end{abstract}

Keywords: approximate digestibility, biomass, consumption, conversion, frass, growth, instar, nymph. 


\section{Introduction}

The desert locust, Schistocerca gregaria (Orthoptera: Acrididae), is a dangerous pest of crops, pastures and agricultural production in Egypt and other countries of North Africa and West Asia (Ammar et al., 2009; Lecoq and Mestre, 1988; SanchezZapata et al., 2007). Current locust control measures are mainly based on organophosphorus pesticides as a result of the banning of organochlorines (Lecoq, 2001). The indiscriminate and excessive uses of such pesticides have dangerous problems, such as the development of insect resistance to insecticides, increased costs, handling hazards, several adverse effects on food, soil, ground water and air as well as carcinogenic, teratogenic and great threats to both human and environmental health (Bughio and Wilkins, 2004; Garriga and Caballero, 2011). For avoiding or limiting these problems, it is necessary to seek environmentally safe, convenient, and low-cost alternative control agents. In this regard, insect growth regulators (IGRs) come as promising agents among the various alternatives. They were manufactured to mimic, block or otherwise interact with the hormonal system of insects (Oetken et al., 2004). Moreover, IGRs have been reported to possess a specific activity spectrum with a novel mechanism not based on a neurotoxic action, like synthetic insecticides (Dhadialla et al., 2005). Depending on the mode of action, IGRs are grouped into juvenoids, antijuvenoids, ecdysteroids and chitin synthesis inhibitors as well as other related compounds (Mondal and Parween, 2000; Tunaz and Uygun, 2004). For the pest control, IGRs have been known to act as insect development inhibitors (AbdelAal, 2003; Farag, 2001; Seth et al., 2004). IGRs are "low risk" compounds with a minor harmful effect on the environment, rendering them important agents in IPM programs (Horowitz and Ishaaya, 2004). Ecdysteroids (Ecdysone agonists) had been found to disrupt the moulting process in insects (Schneider et al., 2003; 2008; Silhacek et al., 1990). In some detail, ecdysone agonists act more slowly than neurotoxic insecticides because they disrupt the hormonal system or disturb the physiological development of insects rather than directly killing them (Biddinger et al., 2006). In addition, they have short persistence in the environment making them promising compounds against many important agriculture and forest pests (Biddinger et al., 2006; Osorio et al., 2008; Smagghe et al., 2003; Sundaram et al., 2002). Chromafenozide $\left(\mathrm{Virtu}^{\circledR}\right)$ is a novel non-steroidal ecdysone agonist (Palli and Retnakaran, 2001; Smith, 2001; Yanagi et al., 2000). It was found very potent against Lepidoptera, but weak or inactive against other insect orders (Nakagawa et al., 2005). Also, the use of this ecdysone agonist, at recommended doses, did not pose any hazards to consumers under the open field conditions (Malhat et al., 2014). In insects, the physiological events that are linked to food consumption and utilization appear to be regulated by neural, endocrine and secretogogue mechanisms (Chapman, 1985). Hormones produced by the brain neurosecretory cells, the corpora cardiaca and corpora allata also control the digestive enzyme production (Prabhu and Sreekumar, 1994). As for examples, in the 
last instar larvae of Spodoptera mauritia, feeding activity is maximum at high Juvenile hormone $(\mathrm{JH})$ titer but when $\mathrm{JH}$ titer declines and the subsequent release of ecdysteroids, the feeding activity decreases (Balamani and Nair, 1992; Mona, 2001). On the other hand, feeding and reproduction in insects are closely related to nutritional factors, the qualitative and quantitative aspects of which have impact on the growth, development and fecundity (Slansky and Scriber, 1985). Therefore, an understanding of the nutritional indices in relation to the effiencies of ingestion, digestion assimilation and conversion by the growing larvae would be useful (Scriber and Slansky, 1981). As defined by some authors (Isman, 2002; Lakshmanan et al., 2012; Pavunraj et al., 2012; Yasui et al., 1998), antifeedant is a chemical that inhibits the feeding without killing the insect pest directly, while it remains near the treated foliage and dies through starvation. Besides their lethal action on insect immature stages and sterility in sexually mature adults, IGRs also inhibit the food consumption and growth of individuals which survive after sublethal treatments. However, the actions of some juvenoids, ecdysteroids and chitin synthesis inhibitors on food consumption and utilization had been studied in various insect species (Bream et al., 1999; Farag, 1988, 1991; Ghoneim et al., 1998; Radwan et al., 1986). For these reasons, the present study was carried out for investigating the food deterrence property of Chromafenozide and its disruptive impact on the food consumption and metabolism in the last $\left(5^{\text {th }}\right)$ nymphal instar of $S$. gregaria.

\section{Materials and methods}

\subsection{The insect culture}

In the current study, the desert locust Schistocerca gregaria (Forskal) was used as an experimental insect. Its culture was originated by a sample of gregarious nymphs from Plant Protection Research Institute, Dokki, Giza, Egypt. As described by Hunter-Jones (1961) and improved by Ghoneim et al. (2009), desert locust was reared in wood cages $(60$ $\times 60 \times 70 \mathrm{~cm}$ ). The bottom of each cage was furnished with a layer of sterilized sand $(20 \mathrm{~cm}$ depth) and provided with 10$15 \%$ humidity to be suitable for egg laying. An electric bulb (100 watt) was used to maintain a continuous photoperiod (12 L: $12 \mathrm{D})$ in each cage as well as in order to maintain an ambient temperature $\left(32 \pm 2^{\circ} \mathrm{C}\right)$. The culture was raised and handled under the crowded conditions. All insects were provided every day with fresh clean leaves of clover Trifolium alexandrinum.

\subsection{Application of the ecdysone agonist}

Chromafenozide $\left(\mathrm{Virtu}^{\circledR} 5 \%\right)$ is a nonsteroidal agonist of the insect moulting hormone, ecdysone. It was purchased from Sankyo Co., Ltd. Japan. Chemically, it is 3,4-dihydro-5-methyl-2H-1-benzopyran6-carboxylic acid 2-(3,5-dimethylbenzoyl)2-(1,1-dimethylethyl) hydrazide. The last $\left(5^{\text {th }}\right)$ nymphal instar of $S$. gregaria was chosen in the present study. In a preliminary experiment on the same locust, the sublethal doses Chromafenozide 
were determined as 10, 100 and 150 $\mu \mathrm{g} /$ nymph. Chromafenozide was diluted with acetone for preparing these dose levels. Both of the newly moulted female and male nymphs of last instar were topically treated with $1 \mu \mathrm{l}$ acetone containing Chromafenozide onto the prothoracic sternite using Hamilton microsyringe. Control nymphs were topically treated with acetone only. Ten nymphs from both female and male were used as replicates for each treatment. The replicates were kept individually in $1 \mathrm{~L}$ glass jars for observing and determining the food consumption and utilization as described herein.

\subsection{Feeding deterrence}

Antifeedant index (AFI \%) was calculated according to the equation of Ladhari et al. (2013) as follows: AFI $\%=[(\mathrm{C}-\mathrm{T}) /(\mathrm{C}$ $+\mathrm{T})]$ x 100 Where C: amount of food eaten by the control insect. T: amount of food eaten by the treated insect.

\subsection{Parameters of food consumption and utilization}

In the present study, food consumption, digestion, absorption and conversion efficiencies were determined on a daily basis along the last nymphal instar. Body weight of both treated and control nymphs was recorded before and after feeding, fresh food leaves were weighed before introduction to the nymph, and then the fresh weight of remains was recorded after feeding every day. Each nymph was starved for $3 \mathrm{~h}$ before weighing to ensure an empty intestine. For calculating the corrected weight of food intake, known weights of fresh food leaves were left without nymphs for $24 \mathrm{~h}$, under the same laboratory conditions, and re-weighed at the end of this interval. Weight of frass was estimated for each nymph during the last instar. Relative weight gain $(\mathrm{RWG})=$ $\mathrm{mg}$ weight gain during the instar/ days (Johnson and Mundel, 1987) with correction for a single instar. Feeding rate is the amount of food intake per instar along its feeding period; generally expressed on a "per day per unit body mass" basis (Slansky, 1993). Relative consumption rate was calculated according to Slansky (1985) as follows: $\mathrm{RCR}=\mathrm{mg}$ consumed food/ $\mathrm{g}$ mean fresh body weight/ day. According to Waldbauer (1968), the following parameters can be calculated. Approximate digestibility $(\mathrm{AD})=$ [Weight of ingested food - Weight of faeces / Weight of ingested food] X 100. Efficiency of conversion of ingested food to body substance $(\mathrm{ECI})=[$ Weight gain $/$ Weight of ingested food] X 100. Efficiency of conversion of digested food to body substance (ECD): [Weight gain / Weight of ingested food - Weight of faeces] $X$ 100. Assimilation rate $(A R)=R C R \times A D$ (Scriber and Slansky, 1981). Relative metabolic rate (RMR) was calculated according to Slansky (1980) but corrected for fresh weights and for a single nymphal instar as follows: RMR $=$ (mg weight ingested food - weight of faeces) / $\mathrm{g}$ mean fresh body weight / day. These parameters may help to clear the nutritional 
efficiencies which can affect on growth (Johnson and Mundel, 1987; Hinks et al., 1991). Growth rate (GR) can be calculated as follows: $\mathrm{GR}=$ fresh weight gain during feeding period / feeding period $\mathrm{X}$ mean fresh body weight of larvae during the feeding period (Waldbauer, 1968).

\subsection{Data analysis}

Data were analyzed by the Student's $t$ distribution, and refined by Bessel correction (Moroney, 1957) for the test significance of difference between means.

\section{Results}

3.1 Feeding deterrence property of chromafenozide against $S$. gregaria nymphs

As shown by data of Table (1), Chromafenozide exhibited contradictory effects on the feeding capacity of $S$. gregaria nymphs depending on its dose since it acted as antifeedant against female nymphs only at the lowest dose. Antifeedant index was calculated in $0.101 \%$. In contrast, it acted as phagostimulant against female nymphs at the higher two doses (-3.507 and $-3.633 \%$, respectively). In respect of the male nymphs, chromafenozide exhibited a general phagostimulating effect, regardless the dose level $(-2.594,-0.914$ and $-4.656 \%$ at the dose levels 10,100 , $150 \mu \mathrm{g} /$ nymph, respectively).
3.2 Affected food ingestion and consumption of $S$. gregaria nymphs by chromafenozide

With regard to the food eaten along the last nymphal instar of $S$. gregaria females, data of Table (2) exiguously revealed a slightly decreasing food consumption only at the lowest dose as determined in $4055.4 \pm 50.7 \mathrm{mg}$ ( $v s .4063 .6 \pm 68.2 \mathrm{mg}$ of control congeners) or expressed as reduced. Relative Consumption Rate (RCR) as 39.6 \pm 3.26 (compared to $43.2 \pm 4.79$ of controls, with a change $\%$ of -8.33). At the higher two doses, the food consumption remarkably increased (4359.0 \pm 58.3 and $4370.0 \pm 187.2 \mathrm{mg}$, at 100 and $150 \mu \mathrm{g} /$ nymph, respectively, $v s$. $4063.6 \pm 68.2 \mathrm{mg}$ of controls) but RCR was slightly elevated. Concerning the male nymphs, data arranged in Table (3) revealed a significant or insignificant enhancing action of Chromafenozide on the food intake $(3809.2 \pm 22.6$, $3683.3 \pm 32.2$ and $3969.8 \pm 23.3 \mathrm{mg}$ at 10 , 100 and $150 \mu \mathrm{g} / \mathrm{nymph}$, respectively, compared to $3616.6 \pm 55.2 \mathrm{mg}$ of control male nymphs). RCR was slightly promoted in a dose-dependent course (Change \%: 2.68, 3.24 and 21.09 at 10, 100 and $150 \mu \mathrm{g} / \mathrm{nymph}$, respectively). Depending on the data of Table (2), treated female nymphs attained slightly or significantly increasing relative weight gain (RWG) and discharged more fecal pellets. To some extent, similar increasing RWG and fecal production had been recorded for male nymphs (Table 3 ). 
Table (1): Antifeedant index (\%) of chromafenozide against last instar nymphs of $S$. gregaria.

\begin{tabular}{|l|l|c|}
\hline Dose $(\mu \mathrm{g} /$ nymph $)$ & Females & Males \\
\hline 10 & +0.101 & -2.594 \\
\hline 100 & -3.507 & -0.914 \\
\hline 150 & -3.633 & -4.656 \\
\hline Control & --- & --- \\
\hline
\end{tabular}

Table (2): Effect of chromafenozide on body weight gain, food consumption and faeces produced by females of last nymphal instar of $S$. gregaria.

\begin{tabular}{|l|l|l|l|l|l|}
\hline $\begin{array}{l}\text { Dose } \\
(\mu \mathrm{g} / \mathrm{nymph})\end{array}$ & $\begin{array}{l}\text { RWG } \\
(\mathrm{mg} \pm \mathrm{SD})\end{array}$ & $\begin{array}{l}\text { Food consumed } \\
(\mathrm{mg} \pm \mathrm{SD})\end{array}$ & $\begin{array}{l}\text { Faeces produced } \\
(\mathrm{mg} \pm \mathrm{SD})\end{array}$ & $\begin{array}{l}\text { RCR }(\mathrm{x} 100) \\
(\mathrm{mg} \pm \mathrm{SD})\end{array}$ & $\begin{array}{l}\text { Change } \\
\%\end{array}$ \\
\hline 10 & $123.69 \pm 15.1 \mathrm{a}$ & $4055.4 \pm 50.7 \mathrm{a}$ & $1095.2 \pm 15.9 \mathrm{a}$ & $39.6 \pm 3.26 \mathrm{a}$ & -8.33 \\
\hline 100 & $155.27 \pm 3.7 \mathrm{~d}$ & $4359.0 \pm 58.3 \mathrm{~d}$ & $1253.0 \pm 15.6 \mathrm{~d}$ & $45.0 \pm 3.27 \mathrm{a}$ & +4.17 \\
\hline 150 & $138.86 \pm 31.4 \mathrm{a}$ & $4370.0 \pm 187.2 \mathrm{c}$ & $1204.3 \pm 12.5 \mathrm{~d}$ & $50.0 \pm 5.52 \mathrm{a}$ & +15.74 \\
\hline Control & $119.49 \pm 11.75$ & $4063.6 \pm 68.2$ & $1048.6 \pm 50.5$ & $43.2 \pm 4.79$ & --- \\
\hline
\end{tabular}

Mean \pm SD followed with the letter (a): not significantly different ( $P>0.05)$, (c): highly significantly different $(\mathrm{P}<0.01)$, (d): very highly significantly different $(\mathrm{P}<0.001)$. RWG: Relative weight gain. RCR: Relative consumption rate of food.

Table (3): Effect of chromafenozide on body weight gain, food consumption and faeces produced by males of last nymphal instar of $S$. gregaria.

\begin{tabular}{|l|l|l|l|l|l|}
\hline $\begin{array}{l}\text { Dose } \\
(\mu \mathrm{g} / \mathrm{nymph})\end{array}$ & $\begin{array}{l}\text { RWG } \\
(\mathrm{mg} \pm \mathrm{SD})\end{array}$ & $\begin{array}{l}\text { Food consumed } \\
(\mathrm{mg} \pm \mathrm{SD})\end{array}$ & $\begin{array}{l}\text { Faeces produced } \\
(\mathrm{mg} \pm \mathrm{SD})\end{array}$ & $\begin{array}{l}\text { RCR }(\mathrm{x} 100) \\
(\mathrm{mg} \pm \mathrm{SD})\end{array}$ & $\begin{array}{l}\text { Change } \\
\%\end{array}$ \\
\hline 10 & $127.0 \pm 27.61 \mathrm{a}$ & $3809.2 \pm 22.6 \mathrm{~d}$ & $867.0 \pm 89.6 \mathrm{a}$ & $48.6 \pm 5.54 \mathrm{a}$ & +2.68 \\
\hline 100 & $97.55 \pm 15.17 \mathrm{a}$ & $3683.3 \pm 32.2 \mathrm{a}$ & $889.0 \pm 67.4 \mathrm{~b}$ & $46.25 \pm 2.77 \mathrm{a}$ & +3.24 \\
\hline 150 & $88.23 \pm 15.66 \mathrm{a}$ & $3969.8 \pm 23.3 \mathrm{~d}$ & $879.6 \pm 100.3 \mathrm{~b}$ & $54.25 \pm 7.89 \mathrm{a}$ & +21.09 \\
\hline Control & $96.0 \pm 24.21$ & $3616.6 \pm 55.2$ & $786.0 \pm 32.4$ & $44.8 \pm 6.68$ & --- \\
\hline
\end{tabular}

Mean \pm SD followed with the letter (a): not significantly different $(P>0.05)$, (b): significantly different $(\mathrm{P}<0.05)$, (c): highly significantly different $(\mathrm{P}<0.01)$, (d): very highly significantly different $(\mathrm{P}<0.001)$. RWG: Relative weight gain. RCR: Relative consumption rate of food. (b): significantly different $(\mathrm{P}<0.05)$.

\subsection{Impact of chromafenozide on food} digestive, absorptive and conversion efficiencies of S. gregaria nymphs

Depending on the data of Table (4), female nymphs achieved slightly increasing approximate digestibility (AD), in a dose-dependent course (increment \%s: 1.97, 3.88 and 7.24, at 10, $100 \& 150 \mu \mathrm{g} / \mathrm{nymph}$, respectively). The enhanced $\mathrm{AD}$ was proportional to the increasing RCR achieved by treated nymphs and increasing of their fecal production throughout the last instar. In respect of $\mathrm{AD}$ of male nymphs, the present compound exhibited a diverse effect, depending its dose level, since AD slightly increased at the lowest dose but slightly decreased at the medium dose and un-affected at the highest dose (Table 5). 
Table (4): Effect of chromafenozide on the food digestion, absorption and conversion efficiencies of females of last nymphal instar of S. gregaria.

\begin{tabular}{|l|l|l|l|l|l|l|}
\hline $\begin{array}{l}\text { Dose } \\
(\mu \mathrm{g} / \text { nymph })\end{array}$ & $\begin{array}{l}\text { AD } \\
(\mathrm{mg} \pm \mathrm{SD})\end{array}$ & $\begin{array}{l}\text { Change } \\
\%\end{array}$ & $\begin{array}{l}\text { ECI } \\
(\mathrm{mg} \pm \mathrm{SD})\end{array}$ & $\begin{array}{l}\text { Change } \\
\%\end{array}$ & $\begin{array}{l}\text { ECD } \\
(\mathrm{mg} \pm \mathrm{SD})\end{array}$ & $\begin{array}{l}\text { Change } \\
\%\end{array}$ \\
\hline 10 & $73.84 \pm 2.49 \mathrm{a}$ & +1.97 & $26.14 \pm 5.17 \mathrm{a}$ & +3.69 & $35.64 \pm 7.77 \mathrm{a}$ & +34.74 \\
\hline 100 & $75.22 \pm 0.52 \mathrm{a}$ & +3.88 & $19.77 \pm 1.95 \mathrm{a}$ & +3.51 & $26.47 \pm 2.34 \mathrm{a}$ & +0.08 \\
\hline 150 & $77.65 \pm 1.83 \mathrm{a}$ & +7.24 & $19.73 \pm 1.95 \mathrm{a}$ & +3.17 & $22.73 \pm 2.45 \mathrm{a}$ & +14.06 \\
\hline Control & $72.41 \pm 5.21$ & --- & $19.1 \pm 5.0$ & --- & $26.45 \pm 7.42$ & --- \\
\hline
\end{tabular}

Mean \pm SD followed with the letter (a): not significantly different $(\mathrm{P}>0.05)$. AD: Approximate digestibility. ECI: Efficiency of conversion of ingested food. ECD: Efficiency of conversion of digested food.

Table (5): Effect of chromafenozide on the food digestion, absorption and conversion efficiencies of males of last nymphal instar of $S$. gregaria.

\begin{tabular}{|l|l|l|l|l|l|l|}
\hline $\begin{array}{l}\text { Dose } \\
(\mu \mathrm{g} / \text { nymph })\end{array}$ & $\begin{array}{l}\mathrm{AD} \\
(\mathrm{mg} \pm \mathrm{SD})\end{array}$ & $\begin{array}{l}\text { Change } \\
\%\end{array}$ & $\begin{array}{l}\mathrm{ECI} \\
(\mathrm{mg} \pm \mathrm{SD})\end{array}$ & $\begin{array}{l}\text { Change } \\
\%\end{array}$ & $\begin{array}{l}\mathrm{ECD} \\
(\mathrm{mg} \pm \mathrm{SD})\end{array}$ & $\begin{array}{l}\text { Change } \\
\%\end{array}$ \\
\hline 10 & $72.57 \pm 2.16 \mathrm{a}$ & +0.53 & $21.80 \pm 4.43 \mathrm{a}$ & +0.38 & $24.56 \pm 2.44 \mathrm{a}$ & -19.37 \\
\hline 100 & $71.23 \pm 0.70 \mathrm{a}$ & -1.33 & $25.46 \pm 0.48 \mathrm{a}$ & +17.65 & $30.05 \pm 1.20 \mathrm{a}$ & -1.42 \\
\hline 150 & $72.19 \pm 3.61 \mathrm{a}$ & 0.00 & $22.11 \pm 3.42 \mathrm{a}$ & +2.17 & $30.06 \pm 4.57 \mathrm{a}$ & -1.31 \\
\hline Control & $72.19 \pm 3.61$ & --- & $21.64 \pm 4.27$ & --- & $30.46 \pm 6.94$ & --- \\
\hline
\end{tabular}

Mean \pm SD followed with the letter (a): not significantly different ( $P>0.05)$. AD: Approximate digestibility. ECI: Efficiency of conversion of ingested food. ECD: Efficiency of conversion of digested food.

According to data distributed in the same Table (4), efficiency of conversion of ingested food into biomass (ECI) and efficiency of conversion of digested food into biomass $(\mathrm{ECD})$ of females slightly decreased. ECI increased in a reverse dose-dependent course and determined in $3.69,3.51$ and $3.17 \%$ (at $10,100 \& 150$ $\mu \mathrm{g} /$ nymph, respectively) as well as ECD increased as estimated in 34.74 and 14.06 at the low and higher two doses. Similarly, but in no certain course, ECI of male nymphs was promoted by Chromafenozide (increment \%s: 0.38, 17.65 and 2.17 at the increasing dose level, respectively, Table 5). On the contrary, ECD was slightly inhibited, in no précised trend (decrements: $-19.37,-1.42$ and $-1.31 \%$ at 10,100 and $150 \mu \mathrm{g} / \mathrm{nymph}$, respectively, Table 5). Depending on these data, there was a sexual difference in respect of ECD but similar difference had not been appeared in ECI.

\subsection{Influenced food assimilation and growth of $S$. gregaria nymphs by chromafenozide}

To study the food metabolism, two additional parameters (Assimilation Rate, AR, and Relative Metabolic Rate, RMR) may shed some light on the effect of Chromafenozide. As clearly shown by data of Table (6), AR values of both female and male nymphs increased, at the higher two doses, to highly assimilate the absorbed food $(33.85 \pm 3.24$ and $38.83 \pm 5.11 \%$ of females, vs. $31.26 \pm 4.72 \%$ of controls, as well as $32.94 \pm 2.81$ and $39.16 \pm 5.37 \%$ of males, $v s .32 .34 \pm 5.12 \%$ 
of controls). In general, AR increased in a dose-dependent fashion. To some extent,
RMR increased in a similar course, especially at the higher doses.

Table (6): The correlation of GR (x100) to AR (x100) and RMR (x100) as affected by chromafenozide along the last nymphal instar of $S$. gregaria.

\begin{tabular}{|l|l|l|l|l|l|l|}
\hline \multirow{2}{*}{ Dose $(\mu \mathrm{g} / \mathrm{nymph})$} & \multicolumn{2}{|c|}{ GR } & \multicolumn{2}{c|}{ AR } & \multicolumn{2}{c|}{ RMR } \\
\cline { 2 - 7 } & Females & Males & Females & Males & Females & Males \\
\hline 10 & $8.4 \pm 0.9 \mathrm{a}$ & $13.2 \pm 4.0 \mathrm{a}$ & $29.24 \pm 4.55 \mathrm{a}$ & $31.61 \pm 3.66 \mathrm{a}$ & $29.2 \pm 3.0 \mathrm{a}$ & $32.3 \pm 5.0 \mathrm{a}$ \\
\hline 100 & $10.9 \pm 0.2 \mathrm{c}$ & $9.6 \pm 0.1 \mathrm{a}$ & $33.85 \pm 3.24 \mathrm{a}$ & $32.94 \pm 2.81 \mathrm{a}$ & $31.6 \pm 2.0 \mathrm{a}$ & $34.4 \pm 3.0 \mathrm{a}$ \\
\hline 150 & $9.4 \pm 2.9 \mathrm{a}$ & $10.0 \pm 2.3 \mathrm{a}$ & $38.83 \pm 5.11 \mathrm{~b}$ & $39.16 \pm 5.37 \mathrm{a}$ & $36.8 \pm 4.0 \mathrm{a}$ & $42.3 \pm 6.0 \mathrm{~b}$ \\
\hline Control & $9.3 \pm 0.8$ & $9.5 \pm 1.2$ & $31.26 \pm 4.72$ & $32.34 \pm 5.12$ & $31.1 \pm 5.0$ & $32.6 \pm 7.0$ \\
\hline
\end{tabular}

Mean \pm SD followed with the letter (a): not significantly different $(\mathrm{P}>0.05)$, (b): significantly different $(\mathrm{P}<0.05)$, (c): highly significantly different $(\mathrm{P}<0.01)$. GR: Growth rate. AR: Assimilation rate. RMR: Relative metabolic rate.

Reviewing the data of Tables $(2,3,4,5$ and 6) revealed a positive correlation of $\mathrm{AR}$ and RMR to RCR which was easily shown because these parameters were elevated by Chromafenozide, at the higher doses, indicating a high efficacy of nymphs to digest, absorb and assimilate the food which was eaten at high RCR. For investigating the interrelationship between growth and nutritional performance of $S$. gregaria nymphs as affected by chromafenozide, data arranged in Tables (2 and 6) show that the growth rate (GR) increased, in no certain trend $(8.4 \pm 0.9,10.9 \pm 0.2$ and $9.4 \pm 2.9 \%$, at $10,100 \& 150 \mu \mathrm{g} /$ nymph, respectively, $v s$. $9.3 \pm 0.8 \%$ of controls). As clearly shown by data of Tables $(3 \& 6)$, a similar correlation of the relative growth rate with GR was determined for male nymphs. Also, GR of both sexes was generally promoted as both AR and RMR increased, with few exceptions.

\section{Discussion}

Several metabolic parameters had been suggested for measuring the growth rate and development of the consumer and usually used to determine the food utilization (Scriber and Slansky, 1981; Slansky and Scriber, 1985). However, the common three efficiencies are: approximate digestibility (AD), efficiency of conversion of ingested food to biomass (ECI) and efficiency of conversion of digested food to biomass (ECD) (SenthilNathan et al., 2005; Slansky, 1993; Waldbauer, 1968). Food metabolic efficiencies vary widely with the insect species, age (both within and between instars) and sex as well as with different environmental factors.

\subsection{Food deterrence property of chromafenozide against $S$. gregaria nymphs}

Few researchers recorded antifeedant activity or deterrence index of insecticides, insect growth regulators (IGRs) or other compounds against the target insect pests. For examples, osthole and pregnenolone showed significant antifeedant activity against larvae of Spodoptera litura (Kalpana, 2005). Among seventeen monoterpenoids assessed against Pieris 
brassicae $4^{\text {th }}$ instar larvae, the strongest deterrent effect was exhibited by $\alpha$ phellandrene- and $\beta$-ionone (Kordan and Gabryś, 2013). For more examples, see Rani and Sanjayan (2014) for the Atractomorpha crenulata $4^{\text {th }}$ instar nymphs; Barrania (2013) and Rashwan (2013) for Spodoptera littoralis $4^{\text {th }}$ instar larvae. On comparison with those reported results, chromafenozide unexceptionally exhibited contradictory effects on the feeding of the desert locust Schistocerca gregaria nymphs, in the current investigation, depending on its dose since it acted as a weak antifeedant against female nymphs only at the lowest dose $(10 \mu \mathrm{g} /$ nymph $)$ but acted as phagostimulant against them at the higher two doses (100 and $150 \mu \mathrm{g} / \mathrm{nymph}$ ). Moreover, chromafenozide exhibited a phagostimulant activity against the male nymphs, regardless the dose level. To understand the weak antifeedant activity of chromafenozide in the present study, it may stimulate specific 'deterrent' cells in chemoreceptors and also block the firing of 'sugar' receptor cells, which normally stimulate feeding (Blaney et al., 1990; Simmonds et al., 1990). This feeding inhibition might lead to starvation and death of the insect by feeding deterrence alone (Koul and Wahab, 2004). On the other hand, the phagostimulatory action of the present IGR cannot be explicated right now.

\subsection{Food consumption by S. gregaria nymphs as affected by chromafenozide}

Depending on the reported results, food consumption had been significantly reduced in several insect species by various insecticides or IGRs and IGRrelated compounds. For examples, a considerable reduction in the food consumption was determined for Leptinotarsa decemlineata larvae by Flucycloxuron (Szczepanik, 1998), for 5day-old adults of $S$. gregaria by fenitrothion (Ouali-N'goran et al., 2003) and for Callosobruchus muculatus larvae by Cyromazine (Al-Mekhlafi et al., 2012). With regard to $S$. littoralis, feeding of larvae on castor bean leaves treated with Mancozeb, bromoxynil and profenofos (Marzouk et al., 2012), Pyriban (Chlorpyrifos) (Ebeid and Gesraha, 2012), chlorantraniliprole, thiamethoxam and novaluron (Barrania, 2013), rynaxypyr and indoxacarb (Rashwan, 2013), Flufenoxuron and triflumuron (El-Naggar, 2013), chlorfenapyr (Ebeid et al., 2015) or Diazinon and flufenoxuron (El-Helaly and El-bendary, 2015) resulted in significantly reduced food consumption of larvae. In the current study, results of food consumption of last instar nymphs of $S$. gregaria disagreed with those reported results because Chromafenozide exhibited a general promoting action and thus food consumption generally increased. In the present investigation, also, treated nymphs of both sexes attained slightly or remarkably increasing relative weight gain and discharged more fecal pellets. The increasing food consumption could indicate the action of chromafenozide as a digestive attractant, as previously suggested by Piechowicz et al. (2012) for deltamethrin and pyriproxyfen against the adults of Spanish slug Arion lusitanicus. On the other hand, an exceptional case of decreased food consumption was observed in the current investigation for female nymphs of $S$. gregaria only at the lowest dose (10 
$\mu \mathrm{g} / \mathrm{nymph}$ ) of chromafenozide. However, this case of decreasing food consumption can be partly interpreted by the antifeedant activity of this IGR at the lowest dose. Another suggestion might be acceptable since Masih and Vaishya (2014) reported that IGR disturbs the process of chitin synthesis or/and deposition during ecdysis as well as leads to the insect failure to feed, due to displacement of mandibles and labrum or blockage of the gut.

\subsection{Food digestion and absorption} capacity of S. gregaria nymphs as affected by chromafenozide

Another important nutritional parameter is $\mathrm{AD}$, which expresses the digestion and absorption capacity of the insect. AD estimates the percentage of ingested food that is digested and assimilated (Slansky and Scriber, 1985). In the present study, Chromafenozide-treated female nymphs of $S$. gregaria achieved slightly increasing $\mathrm{AD}$, in a dose-dependent course. Chromafenozide exhibited a diverse effect on $\mathrm{AD}$ of male nymphs, depending on the concentration. The male nymphs achieved a slightly increased $\mathrm{AD}$ at the lowest dose but a slightly decreased $\mathrm{AD}$ at the medium dose and un-affected $\mathrm{AD}$ at the highest dose. The present results of females and partially of males were, to some extent, in agreement with those reported results of remarkably increased AD (Abou El- Ghar et al., 1996; Bream et al., 1999; Garside et al., 2000). Also, after topical application of different doses of Hydroprene onto the last $\left(6^{\text {th }}\right)$ instar larvae of Spodoptera mauritia, AD increased (Sindhu and Nair, 2004). AD of $4^{\text {th }}$ instar larvae of $S$. littoralis was enhanced by chlorfenapyr, at $0.25 \%$ concentration (Ebeid et al., 2015). On the contrary, the present results of the enhancing action of Chromafenozide on AD of $S$. gregaria nymphs had not been consistent with some reported results of inhibited $\mathrm{AD}$ in some insects by various IGRs and insecticides. Fore examples, pronouncedly reduced $\mathrm{AD}$ was recorded for S. gregaria nymphs after treatment with fenoxycarb (Ismail, 1995) and for $S$. littoralis larvae after treatment with teflubenzuron (Abdel-Aal and AbdelKhalek, 2006), Sumialfa (El-Malla and Radwan, 2008) or rynaxypyr and indoxacarb (Rashwan, 2013). However, the present results had shown an exceptional case of un-affected AD of male nymphs (at the highest dose of Chromafenozide). This result came in agreement with those reported results of unchanged $\mathrm{AD}$ of few insects by certain compounds, such as $H$. virescens larvae after feeding on tobacco plants, expressing potato proteinase inhibitors (PIN-2) (Brito et al., 2001) and the $4^{\text {th }}$ instar larvae of $S$. littoralis after feeding on food treated with $\mathrm{LC}_{\mathbf{5 0}}$ of flufenoxuron or Triflumuron (El-Naggar, 2013). The prevalent enhancing action of Chromafenozide on $\mathrm{AD}$ of $S$. gregaria nymphs, in the current study, could be interpreted as earlier suggested as attempts made by the insect to compensate for the reduced consumption and utilization of food in order to maintain growth rate (Reese and Beck, 1976). Generally, increasing $\mathrm{AD}$ could be understood in the light of increasing RCR as well as increasing amounts of food eaten by treated nymphs in the current work. The exceptional result of inhibited $\mathrm{AD}$ of male nymphs, in the present study, 
should not be neglected because inhibition or reduction of $\mathrm{AD}$ might be due to the toxicity of chromafenozide on the digestive cells causing a damage of the gut epithelium, and so treated insects are unable to digest food properly (Meyer and Lamberts, 1965) and the food absorption capacity might be impaired (Abu ElEla and ElSayed, 2015; Baghban et al., 2014).

\subsection{Influenced food conversion} efficiencies of $S$. gregaria nymphs by chromafenozide

In insects, ECI measures the overall ability of insect to convert ingested food into the body tissues while ECD is the conversion capacity of digested food into biomass. In the present study, ECIs of both female and male nymphs of $S$. gregaria had been enhanced by Chromafenozide. Similarly, ECD of female nymphs had been enhanced. These results were, to some extent, in agreement with reported results of enhanced ECI in few insects, since significantly increasing ECI was recorded in the last instar larvae of $S$. mauritia after topical application with hydroprene (Sindhu and Nair, 2004) and in the last instar larvae of S. littoralis after treatment with Cadmium (Abu ElEla and ElSayed, 2015). In contrast, chromafenozide exhibited an inhibitory effect on ECD in the male nymphs only, in the current work. However, ECI and ECD of various insect species had been considerably or slightly inhibited by different insecticides and IGRs, such as fenarimol (Farag, I991), tebufenozide (Bream et al., 1999), Sumialfa (El-Malla and Radwan, 2008), flufenoxuron and triflumuron (El-Naggar, 2013) or rynaxypyr and indoxacarb (Rashwan,
2013) against S. littoralis larvae. Also, treatment of $S$. littoralis larvae with $\mathrm{LC}_{50}$ of Diazinon and flufenoxuron (El-Helaly and El-bendary, 2015) or the low concentration of chlorfenapyr (Ebeid et al., 2015) resulted in remarkably inhibited ECI and ECD. In the present study, enhanced ECI and ECD of $S$. gregaria nymphs, after treatment with Chromafenozide, might be understood because the insect requires a lot of energy to deal with the used chemical toxicity, as suggested by Emre et al. (2013) for Galleria mellonella, Baghban et al. (2014) for H. armigera and Abu ElEla and ElSayed (2015) for S. littoralis. On the other hand, the inhibited ECD might indicate that the ingested Chromafenozide exhibited some chronic toxicity against the insect (Wheeler and Isman, 2001). In this respect, El-Shazly (1993) indicated that ECI will vary with the digestibility of food and proportional amount of the digestible portion of food which is converted to body substance and metabolized for energy to maintain life.

\subsection{Influenced food assimilation in $S$. gregaria nymphs by chromafenozide}

From the metabolic view of point, additional nutritional parameters had been reported, viz. Assimilation rate (AR) and Relative metabolic rate (RMR). These parameters may help to clear the metabolic efficiencies which can affect the growth (Hinks et al., 1991). In the current study, AR of both female and male nymphs of $S$. gregaria increased after treatment with Chromafenozide, especially with the higher two doses, to highly assimilate the absorbed food. RMR was promoted, especially at the higher 
doses. A positive correlation of $\mathrm{AR}$ and RMR to RCR was easily detected for $S$. gregaria nymphs. These results were in contrast to several reported results of regressed $A R$ and $R M R$ in larvae of various insect species by the action of some IGRs, such as Agrotis ipsilon (Reese and Beck, 1976), Manduca sexta (Dahlman, 1977), S. litura (Sundaramurthy, 1977), S. littoralis (Bream et al., 1999) and S. gregaria (Ismail, 1995). These differences might be due to the difference of IGRs, method of treatment and the response of the insect.

\subsection{Growth in relation to the nutritional efficiencies of $S$. gregaria nymphs as affected by chromafenozide}

As reported for many insects, relative weight gain (RWG) or/and growth rate (GR) had been reduced by several insecticides or IGRs and IGR-related compounds. As for examples, GR of $S$. littoralis $4^{\text {th }}$ instar larvae was significantly reduced after treatment with some IGRs (El-Basyouni and Sharaf, 2002), or chlorantraniliprole, thiamethoxam and Novaluron (Barrania, 2013), or flufenoxuron and Triflumuron (ElNaggar, 2013), or rynaxypyr and indoxacarb (Rashwan, 2013), or Diazinon and flufenoxuron (El-Helaly and Elbendary, 2015). Also, Chlorpyrifos showed stronger growth inhibitory action than deltamethrin in A. crenulata (Rani and Sanjayan, 2014). In contrast to these reported results of inhibited GR, GR of both sexes of $S$. gregaria nymphs, in the present study, was generally enhanced by chromafenozide since both AR and RMR increased, with few exceptions. Also, GR was positively correlated with RWG.
However, our results were, to a great extent, in agreement with the enhancement of larval growth by IGRs as reported in some insects since topical treatment of the last instar larvae of $S$. mauritia with different doses of Hydroprene resulted in an increase of GR (Sindhu and Nair, 2004) while Novaluron exhibited a reversible effect on the larval RWG and GR of S. littoralis, depending on the concentration (Ghoneim et al., 2015). The interpretation of inhibited growth of various insects after treatment with IGRs or IGR-related compounds had been available in the literature (Martinez and van Emden, 1999; Marie et al., 2009; Mehrkhou, 2013; Abu ElEla and ElSayed, 2015; Giongo et al., 2015). Unfortunately, an acceptable interpretation of the enhanced growth of S. gregaria nymphs, as recorded in the present study after treatment with Chromafenozide, could not be provided right now.

\subsection{Frass production by S. gregaria as influenced by chromafenozide}

It is important to point out that the feeding is necessary for the stimulation of digestive enzyme activities in insects (Smirle et al., 1996) and may have interfered with the enzyme-substrate complex thus affecting the peristaltic movement of the alimentary canal (Broadway, and Duffey, 1988). Some IGRs prohibited the fecal production by insects. For examples, the $S$. littoralis larvae produced remarkably reduced frass amount after treatment with fenarimol or naurimol (Farag, 1991), tebufenozide (Bream et al., 1999) or Lufenuron (Adel, 2012). Also, reduction of frass production was recorded for $S$. gregaria after 
treatment with fenoxycarb (Ismail, 1995) and for S. mauritia after treatment with diflubenzuron (Jagannadh and Nair, 1997). The present results disagreed with those reported results because the fecal production by chromafenozide-treated nymphs of $S$. gregaria increased and had been proportional to their increased RCR the enhanced $\mathrm{AD}$. We are unable right now to provide a conceivable explanation to the increasing fecal production and the matter is still obscure. However, the increasing fecal production might indicate higher capacity of $S$. gregaria nymphs to digest, absorb and assimilate the ingested food as a response to chromafenozide.

\section{Conclusion}

As clearly shown in the present study, chromafenozide exhibited a weak antifeedant activity, only at the lowest dose level, against the last instar nymphs of $S$. gregaria. At its dose level, this IGR exerted a slight inhibitory action of the food consumption but enhanced the nymphs to eat more food amounts, gained increased somatic weight and discharged more fecal pellets. Also, it failed to pronouncedly inhibit the food digestibility, conversion and assimilation capacities of the treated nymphs, at the higher dose levels. Depending on these results, chromafenozide cannot be considered as a promising agent for controlling this pest.

\section{References}

Abdel-Aal, A. E. (2003), Effect of some insect growth regulators on certain biological, biochemical and histopathological aspects of the cotton leafworm, Spodoptera littoralis (Boisd.) Ph.D. Thesis, Faculty of Science, Cairo University, Egypt.

Abdel-Aal, A. E. and Abdel-Khalek, A. (2006), "Effect of three insect growth regulators on some biological and physiological aspects of Spodoptera littoralis (Boisd.)", Bulletin of the Entomological Society of Egypt / Economic series, Vol. 32, pp. 101112.

Abou El-Ghar, G. E. S., Khalil, M. E. and Eid, T. M. (1996), "Some biochemical effect of plant extracts in the black cutworm Agrotis ipsilon (Hufinagel) (Lepidoptera: Noctuidae)", Journal of Applied Entomology, Vol. 120 No.8, pp. 477499 .

Abu ElEla, Sh. A. and ElSayed, W. M. (2015), "The Influence of Cadmium on the food consumption and utilization of the cotton leaf worm Spodoptera littoralis (Boisd.) (Lepidoptera: Noctuidae)", Ecologia Balkanica, Vol. 7 No. 1, pp. 81-85.

Adel, M. M. (2012), "Lufenuron impair the chitin synthesis and development of Spodoptera littoralis Boisd (Lepidoptera: Noctuidae)", Journal of Applied Sciences Research, Vol. 8 No. 5, pp. 2766-2775.

Al-Mekhlafi, F. A., Mashaly, A. M. A., Ebaid, H., Wadaan, M. A. and AlMallah, N. M. (2012), "Control of the seed beetle Callosobruchus 
muculatus reared on chickpeas by different applicable conditions of the insect growth regulator, Cyromazine", Scientific Research and Essays, Vol.7 No.1, pp. 55-60.

Ammar, M., Ben Hamouda, A., Kallel, S., Moumene, K. and Ben Hamouda, $M$. H. (2009), "Phase characteristics of the desert locust Schistocerca gregaria swarming populations during the 2004 outbreak in Tunisia and that of 2005 in Algeria", Tunisian Journal of Plant Protection, Vol. 4 No.2, pp. 145-156.

Baghban, A., Sendi, J., Zibaee, A. and Khosravi, R. (2014), "Effect of heavy metals $(\mathrm{Cd}, \mathrm{Cu}$, and $\mathrm{Zn})$ on feeding indices and energy reserves of the cotton boll worm Helicoverpa armigera Hübner (Lepidoptera: Noctuidae)", Journal of Plant Protection Research, Vol. 54 No.4, pp. 367-373.

Balamani, E. and Nair, V. S. K. (1992), "Inhibitory effects of a juvenile hormone analogue on prothoracic gland activity in the penultimate and last instar larval development of Spodoptera mauritia Boisd. (Lepidoptera: Noctuidae)", Zoologischer Anzeiger, Vol. 228, pp. 182.

Barrania, A. A. (2013), "Antifeedant, growth inhibitory and toxicity effects of chlorantraniliiprole, thiamethoxam and novaluron against the cotton leafworm, Spodoptera littoralis (Boisd.) (Lepidoptera: Noctuidae) in cotton fields", Egyptian Journal of Agricultural
Research, Vol. 91 No. 3, pp. 903911.

Biddinger D., Hull, L., Huang, H., McPheron, B. and Loyer, M (2006), "Sublethal effects of chronic exposure to tebufenozide on the development, survival, and reproduction of the tufted apple bud moth (Lepidoptera: Tortricidae)", Journal of Economic Entomology, Vol. 99, pp.834-842.

Blaney, W.M., Simmonds, M.S.J., Ley, S.V., Anderson, J.C. and Toogood, P.L. (1990), "Antifeedant effects of azadirachtin and structurally related compounds on lepidopterous larvae", Entomologia Experimentalis et Applicata, Vol. 55, pp.149-160.

Bream, A. S., Ghoneim, K. S. and Mohamed, H. A. (1999), "Food metabolic changes in larvae of Spodoptera littoralis (Boisd.) (Lepidoptera: Noctuidae) induced by tebufenozide", Bulletin of the Entomological Society of Egypt / Economic series, Vol. 26, pp. 11-24 .

Brito, L. O., Lopes, A. R., Parra, J. R. P., Terra, W. R. and Silva-Filho, M. C. (2001), "Adaptation of tobacco budworm Heliothis virescens to proteinase inhibitors may be mediated by the synthesis of new proteinases", Comparative Biochemistry and Physiology - Part $B$, Vol. 128 No. 2, pp. 365-375.

Broadway, R. M. and Duffey, S. S. (1988), "The effect of plant protein quality on insect digestive 
physiology and the toxicity of plant proteinase inhibitors", Journal of Insect Physiology, Vol. 34, pp. 11111117.

Bughio, F. M. and Wilkins, R. M. (2004), "Influence of malathion resistance status on survival and growth of Tribolium castaneum (Coleoptera: Tenebrionidae), when fed on flour from insect resistant and susceptible grain rice cultivars", Journal of Stored Products Research, Vol. 40, pp. 65-75.

Chapman, R. F. (1985), "Structure of digestive system", In: Comprehensive insect physiology, biochemistry and pharmacology, Kerkut, G.A. and L.I. Gilbert (eds.), Pergamon Press, Oxford, Vol. 4, pp. 165.

Dahlam, D. L. (1977) "Effect of Lcanavanine on the consumption and utilization of artificial diet by the tobacco hornworm, Manduca sexta", Entomologia Experimentalis et Applicata, Vol. 22, pp. 123-131 .

Dhadialla, T. S., Retnakaran, A. and Smagghe, A. (2005), "Insect growthand developmental-disturbing insecticides", In: Comprehensive Molecular Insect Science, Gilbert, L.I., Iatrou, K. and Gill, S.K. (eds.), Elsevier, Oxford, Vol. 6, pp. 55-116.

Ebeid, A. R. and Gesraha, M. A. (2012), "Impact of three commercial insecticides on some biological aspects of the cotton leafworm, Spodoptera littoralis (Lepidoptera: Noctuidae)", Journal of Applied
Sciences Research, Vol.8 No. 5, pp. 2620-2625.

Ebeid, A. R., Sammour, E. A. and Zohdy, N. Z. M. (2015), "Role of Challenger pesticide and plant extracts on some physiological parameters of the cotton leafworm, Spodoptera littoralis (Boisd.)", Archives of Phytopathology and Plant Protection, Vol. 48 No. 5, pp. 385-392.

El-Basyouni, S. A. and Sharaf, F. H. (2002), The effect of some insect growth regulators (IGRs) on the consumption, digestion and utilization of food by the cotton leafworm Spodoptera littoralis, The $2^{\text {nd }}$ International Conference, Plant Protection Research Institute, Cairo, Egypt, Vol. 1, pp. 742-744.

El-Helaly, A. A. and El-bendary, H. M. (2015), "Field study to evaluate the joint action of certain insecticides, IGR's and baculoviruses against Spodoptera littoralis (Bosid.)", Journal of Entomology and Zoology Studies, Vol. 3No. 6, pp. 289-293.

El-Malla, M. A. and Radwan, E. M. M. (2008), "Residual toxicity of abamectin and spinosad insecticides on the cotton leafworm, Spodoptera littoralis (Boisd.)", Bulletin of the Entomological Society of Egypt / Economic series, Vol. 34, pp. 119129.

El-Naggar, J.B.A. (2013), "Sublethal effect of certain insecticides on biological and physiological aspects of Spodoptera littoralis (Boisd.)", 
Nature and Science, Vol. 11 No. 7, pp. 19-25.

El-Shazly, N. M. (1993), "Quantitative evaluation of food intake and assimilation by Spilostethus pandurus (Scopoli), (Hemiptera: Lygaeidae)", Bulletin of the Entomological Society of Egypt / Economic series, Vol. 71, pp. 109117.

Emre, I., Kayis, T., Coskun, M., Dursun, O. and Cogun, H. (2013), "Changes in antioxidative enzyme activity, glycogen, lipid, protein, and malondialdehyde content in cadmium-treated Galleria mellonella larvae", Annals of the Entomological Society of America, Vol. 106 No. 3, pp. 371-377.

Farag, A.I. (1988), "Action of fluoromevalonate and hydroprene on consumption and utilization of food by Pieris brassicae (L.) following larval treatment", In: Endocrinological Frontiers in Physiological Insect Ecology, F. Sehnal, A. Zabza and Danlinger, D.L. (Eds), Wrocław University of Science and TechnologyPress, Poland.

Farag, A. I. (1991), "Inhibition of feeding rates and utilization efficiency in Spodoptera Iittoralis larvae by two compounds with anti-ecdysone activity", Annals of Agricultural Sciences, Vol. 29 No. 1, pp. 609-621.

Farag, A. M. (2001), Biochemical studies on the effect of some insect growth regulators on the cotton leafworm, M.Sc. Thesis, Faculty of Agriculture, Cairo University, Cairo, Egypt.

Garriga, M. and Caballero, J., (2011), "Insights into the structure of urealike compounds as inhibitors of the juvenile hormone epoxide hydrolase (JHEH) of the tobacco hornworm Manduca sexta: Analysis of the binding modes and structure-activity relationships of the inhibitors by docking and CoMFA calculations", Chemosphere, Vol. 82, pp. 1604 1613.

Garside, C. S., Nachman, R. I. and Tobe, S. S. (2000), "Injection of Dipallatosatin or Dip-allatostatin pseudopeptide into mated female Diploptera punctata inhibits endogenous rates of III biosynthesis and basal oocyte growth. Insect Biochem", Molecular Biology, Vol. 30, pp.703-710.

Ghoneim, K. S., Bream, A. S. and Mohamed, H. A. (1998), "Bioactivity of the ecdysteroid agonist, Tebufenozide (RH-5992) on the Egyptian cotton leafworm Spodoptera littoralis Boisd. (Noctuidae: Lepidoptera)", Al-Azhar Bulletin of Science, Vol. 9 No. 2, pp. 947-963.

Ghoneim, K. S., Tanani, M. A. and Basiouny, A. L. (2009), "Influenced survival and development of the desert locust Schistocerca gregaria (Acrididae) by the wild plant Fagonia bruguieri (Zygophyllaceae)", Egyptian Academic 
Journal of Biological Science, Vol. 2 No. 2, pp. 147-164.

Ghoneim, K., Tanani, M., Hamadah, Kh., Basiouny, A. and Waheeb, H. (2015), "Bioefficacy of Novaluron, a chitin synthesis inhibitor, on survival and development of Spodoptera littoralis (Boisd.)(Lepidoptera: Noctuidae)", Journal of Advances in Zoology, Vol. 1 No. 1, pp. 24-35.

Giongo, A. M. M., Vendramim, J. D., De Freitas, S. D. L. and Da Silva, M. F. G. F. (2015), "Growth and nutritional physiology of Spodoptera frugiperda (Lepidoptera: Noctuidae) fed on Meliaceae fractions", Revista Colombiana de Entomología, Vol. 41 No. 1, pp. 33-40.

Hinks, C. F, Cheeseman, M. T., Erlandson, M. A., Olfert, O. and Westcott, N. D. (I991), "The effects of Kochia, wheat and oats on digestive protinases and the protein economy of adult grasshopper Melanoplus Melanoplus senguinipes", Journal of Insect Physiology, Vol. 37, pp. 417-430.

Hunter-Jones, P. (1961), Rearing and breeding locusts in the laboratory, Bulletin of Anti-Locust Research Centre, London, United Kingdom, pp.12.

Ismail, I. E. (1995), "Effect of fenoxycarb on the food consumption and utilization of last nymphal instar of the desert locust, Schistocerca gregaria (Forsk). (Orthoptera: Acrididae)", Journal of the Faculty of
Education- Ain Shams University, Vol. 19, pp. 65-73 .

Isman, M. (2002), "Insect antifeedants", Pesticide Outlook, Vol. 13, pp. 152157.

Jagannadh, V. and Nair, V. S. K. (1997), "Food consumption and utilization by diflubenzuron treated larvae of Spodoptera mauritia (Boisd.) (Lepidoptera: Noctuidae)", Annals of Plant Protection Sciences, Vol. 5 No. 1 , pp. $40-43$.

Johnson, D. and Mundel, H. (1987), "Grasshopper feeding rats, preferences and growth on sawflower", Annals of Applied Biology, Vol. 11No. 1, pp. 43-52.

Kalpana, R. (2005), Feeding deterrent and growth inhibitory properties of Coumarin and Sterol against Spodoptera litura (Fab.) (Lepidoptera: Noctuidae), M.Sc. Thesis, University of Madras, Chennai, India.

Kordan, B. and Gabryś, B. (2013), "Feeding deterrent activity of natural monoterpenoids against larvae of the large white butterfly Pieris brassicae (L.)", Polish Journal of Natural Sciences, Vol. 28 No. 1, pp. 63-69.

Ladhari, A., Laarif, A., Omezzine, F. and Haouala, R. (2013), "Effect of the extracts of the spiderflower, Cleome arabica, on feeding and survival of larvae of the cotton leaf-worm, Spodoptera littoralis", Journal of Insect Science, Vol. 13, pp. 61. 
Lakshmanan, S., Krishnappa, K. and Elumalai, K. (2012), "Certain plant essential oils against antifeedant activity of Spodoptera litura (Fab.), Helicoverpa armigera (Hub.) and Achaea janata (Linn.) (Lepidoptera: Noctuidae", International Journal of Current Life Sciences, Vol. 2 No. 1, pp. 5-11.

Lecoq, M. (2001), "Recent progress in desert and migratory locust management in Africa. Are preventive actions possible?", Journal of Orthoptera Research, Vol. 10 No. 2, pp. 277-291.

Malhat, F., Badawy, H. M. A., Barakat, D. A. and Saber, A. N. (2014), "Residues, dissipation and safety evaluation of chromafenozide in strawberry under open field conditions", Food Chemistry, Vol. 152 No. 1, pp. 18-22.

Marie, S. S., Amr, E. M. and Salem, N. Y. (2009), "Effect of some plant oils on biological, physiological and biochemical aspects of Spodoptera littoralis (Boisd.)", Research Journal of Agriculture and Biological Sciences, Vol. 5 No. 1, pp. 103-107.

Martinez, S. S. and van Emden, H. F. (1999), "Sublethal concentrations of azadirachtin affect food intake, conversion efficiency and feeding behaviour of Spodoptera littoralis (Lepidoptera: Noctuidae)", Bulletin of Entomological Research, Vol. 89, pp. 65-71.

Marzouk, E. A., Megahed, M. M. M.,
Abouamer, W. L. and El-Bamby, M. M. (2012),"Effects of three pesticides on some biological aspects of cotton leaf worm (Spodoptera littoralis Boisd.) larvae under laboratory conditions", Journal of Plant Protection and Pathology, Vol. 3 No. 12, pp. 1345-1352.

Masih, S. C. and Vaishya, J. K. (2014), "Effect of Insect growth regulators on weight loss of the Lepidopterous pests", Asian Journal of Advanced Basic Sciences, Vol. 3 No. 1, pp. 3642.

Mehrkhou, F. (2013), "Effect of soybean varieties on nutritional indices of beet armyworm Spodoptera exigua (Lepidoptera: Noctuidae)", African Journal of Agricultural Research, Vol. 8 No. 16, pp. 1528-1533.

Mona, P. M. (2001), On the developmental profile of hormones in Spodoptera mauritia Boisd. (Lepidoptera: Noctuidae), Ph.D. Thesis, University of Calicut, Calicutm, India.

Mondal, K. and Parween, S. (2000), "Insect growth regulators and their potential in the management of stored-product insect pests", Integrated Pest Management Reviews, Vol. 5, pp. 255-295.

Nakagawa, Y., Takahashi, K., Kishikawa, H., Ogura, T., Minakuchi, C. and Miyagawa, H. (2005), "Classical and three-dimensional QSAR for the inhibition of $[3 \mathrm{H}]$ ponasterone $\mathrm{A}$ binding by diacylhydrazine-type 
ecdysone agonists to insect Sf-9 cells", Bioorganic \& Medicinal Chemistry, Vol. 13, pp. 1333-1340

Oetken, M., Bachmann, J., SchulteOehlmann, U. and Oehlmann, J. (2004), "Evidence for endocrine disruption in invertebrates", International Review of Cytology, Vol. 236, pp. 1-44.

Osorio, A., Martínez, A. M., Schneider, M. I., Díaz, O., Corrales, J. L., Avilés, M. C., Smagghe, G. and Pineda, S. (2008), "Monitoring of beet armyworm resistance to spinosad and methoxyfenozide in Mexico", Pest Management Science, Vol. 64, pp. 1001-1007.

Ouali-N'goran, S. W. M., Kouassi, K. P. H., Koua, K. H. and Fouabi, K. (2003), Effet des doses sublétales fénitrothion sur le comportement alimentaire et la fécondité $d u$ criquet pèlerin Schistocerca gregaria (Forskal, 1775), Bioterre, Rev. Inter. Sci. de la Vie et de la Terre, $\mathrm{N}^{\circ}, 200$ Eds Univ. de Côte d'Ivoire, Vol. 3 No.1, pp. 117-129.

Pavunraj, M., Baskar, K. and Ignacimuthu, S. (2012), "Efficacy of Melochia corchorifolia L. (Sterculiaceae) on feeding behaviour of four Lepidopteran pests", International Journal of Agricultural Research, Vol. 7 No. 2, pp. 58-68.

Piechowicz, B., Stawarczyk, K. and Stawarczyk, M. (2012), "Insecticide and food consumption of Spanish slug (Arion lusitanicus Mabille
1868)", $\quad$ Chemistry-DidacticsEcology-Metrology, Vol. 17 No. 1-2, pp.113-120.

Radwan, H. S. A., Assal, O. M., AboElghar, G. E., Riskallah, M. R. and Ahmed, M. T. (1986), "Some aspects of the action of diflubenzuron and trifluron on food consumption, growth rate and food utilization by Spodoptera littoralis larvae", Journal of Insect Physiology, Vol. 32, pp. 103-407.

Rani, R. J. and Sanjayan, K. P. (2014), "Antifeedant and growth inhibitory effects of Chlorpyrifos and deltamethrin on the tobacco grasshopper, Atractomorpha crenulata (Fabricius 1973)", International Journal of Current Research in Chemistry and Pharmaceutical Sciences, Vol. 1 No. 3, pp. 55-57.

Rashwan, M. H. (2013), "Impact of certain novel insecticides on food utilization, ingestion and larval growth of the cotton leafworm Spodoptera littoralis (Boisd.)", New York Science Journal, Vol. 6 No. 8 , pp. 1-7.

Reese, J. C. and Beck, S. D. (1976), "Effects of allelochemics on the black cutwonn, Agrotis ipsilon: effects of benzoquinone, hydroquinone and duroquinone on larval growth, development and utilization of food", Annals of the Entomological Society of America, Vol. 69, pp. 59-67.

Sanchez-Zapata, J. O., Donazar, J. A., 
Delgado, A., Forero, M. G., Ceballos, O. and Hiraldo, F. (2007), "Desert locust outbreaks in the Sahel: resource competition, predation and ecological effects of pest control", Journal of Applied Ecology, Vol. 44 No. 2, pp. 323-329.

Schneider M. I., Smagghe G., Gobbi A. and Viñuela, E. (2003), "Toxicity and pharmacokinetics of insect growth regulators and other novel insecticides on pupae of Hyposoter didymator (Hymenoptera: Ichneumonidae), a parasitoid of early larval instars of Lepidopteran pests", Journal of Economic Entomology, Vol. 96, pp.1054-1065.

Schneider, M. I., Smagghe, G., Pineda, S. and Viñuela, E. (2008), "The ecological impact of four IGR insecticides in adults of Hyposoter didymator (Hym., Ichneumonidae)", Ecotoxicology, Vol. 17, pp. 181-188.

Scriber, J. M. and Slansky, F. Jr. (1981), "The nutritional ecology of immature insects", Annual Review of Entomology, Vol. 26, pp.183-211.

Senthil, N. S., Chung, P. G. and Murugan, K. (2005), "Effect of biopesticides applied separately or together on nutritional indices of the rice leaffolder Cnaphalocrocis medinalis (Guenée) (Lepidoptera: Pyralidae)", Phytoparasitica, Vol. 33, pp. 187195.

Seth, R. K., Kaur, J. J., Rad, D. K. and Reynolds, S. E. (2004), "Effect of larval exposure to sublethal concentrations of the ecdysteroid agonists RH-5849 and Tebufenozide (RH-5992) on male reproductive physiology in Spodoptera litura", Journal of Insect Physiology, Vol. 50 No. 6, pp. 505-517.

Silhacek, L., Oberlander, H. and Porcheron, P. (1990), "Action of RH5849, a non-steroidal ecdysteroid mimic on Plodia interpunctella (Hübner) in vivoand in vitro", Archives of Insect Biochemistry and Physiology, Vol. 15, pp. 201-212.

Simmonds, M. S. J., Blaney, W. M., Delle Monache, F. and Marini-Bettolo, G. B. (1990), "Insect antifeedant activity associated with compounds isolated from species of Lonchocarpus and Tephrosia", Journal of Chemical Ecology, Vol.16, pp. 365-380.

Sindhu, A. and Nair, V. S. K. (2004), "Influence of juvenile hormone analogue on food consumption and digestive enzyme activities in Spodoptera mauritia Boisd", Indian Journal of Experimental Biology, Vol. 42, pp. 491-494.

Slansky, F. Jr. (1980), "Quantitative food utilization and reproductive allocation by adult milkweed bugs, Oncopeltus fasciatus", Physiological Entomology, Vol. 5, pp.73-86.

Slansky, F. Jr. (1985), "Food utilization by insects: interpretation of observed differences between dry weight and energy efficiencies", Entomologia Experimentalis et Applicata, Vol. 39, 
pp. 47-60.

Slansky, F. Jr. (1993), "Nutritional Ecology: the fundamental quest for nutrients", In: Caterpillars: Ecology and Evolutionary Constraints on Foraging, Stamp, N.E. and Casey, T.M. (eds), Chapman Hall, N.Y, USA, pp. 29-91.

Smagghe, G., Pineda, S., Carton, B., Del Estal, P., Budia, F. and Viñuela, E. (2003), "Toxicity and kinetics of methoxyfenozide in greenhouseselected Spodoptera exigua (Lepidoptera: Noctuidae)", Pest Management Science, Vol. 59, pp. 1203-1209.

Smirle, M. J., Lowery, D. T. and Zurowski, C. L. (1996), "Influence of neem oil on detoxication enzyme activity in the oblique-banded leafroller, Choristoneura rosaceana, Pestic", Biochemistry and Physiology, Vol. 56, pp. 220-230.

Sundaram, M., Palli, S. R., Smagghe, G., Ishaaya, I., Feng, Q. L., Primavera, M., Tomkins, W. L., Krell, P. J. and Retnakaran, A. (2002), "Effect of RH-5992 on adult development in spruce budworm, Choristoneura fumiferana", Insect Biochemistry and Molecular Biology, Vol. 32, pp. 225231.

Sundaramurthy, V. T. (1977), "Effect of inhibitors of chitin deposition on the growth and differentiation of tobacco caterpillar Spodoptera litura Fb. (Noctuidae: Lepidoptera)", Z Pflanzenkrankheith und
Pflanzenschutz, Vol. 84 No. 10, pp. 597-601.

Szczepanik, M. (1998), "Effect of flucycloxuron on the food consumption and growth rate of the Colorado beetle, Leptinotarsa decemlineata Say larvae", Progress in Plant Protection, Vol. 38 No. 2, pp. 385-388.

Tunaz, H. and Uygun, N. (2004), "Insect growth regulators for insect pest control", Turkish Journal of Agriculture and Forestry, Vol. 28, pp. 337-387.

Waldbauer, G. P. (1968), "The consumption and utilization of food by insects", Advances in Insect Physiology, Vol. 5, pp. 229-288.

Wheeler, D. A. and Isman, M. B. (2001), "Antifeedant and toxic activity of Trichilia americana extract against the larvae of Spodoptera litura", Entomologia Experimentalis et Applicata, Vol. 98, pp. 9-16.

Woodring, J. P., Clifford, C. W. and Beckman, B. R. (1979), "Food utilization and metabolic efficiency in larval and adult house crickets", Journal of Insect Physiology, Vol. 25, pp. 903-912.

Yasui, H. A., Kato, A. and Yazawa, M. (1998), "Antifeedant to armyworm, Spodoptera litura and Pseudaletia separata, from bitter ground leaves, Momordica charantia", Journal of Chemical Ecology, Vol. 24 No. 5, pp. 803-813. 